\title{
Synergic effects of histology subtype, lymph node metastasis, and distant metastasis on prognosis in differentiated thyroid carcinoma using the SEER database
}

\author{
Ling Zhou ${ }^{1 \#}$, Qianqian Li $^{1 \#}$, Sichao Chen ${ }^{1}$, Yihui Huang ${ }^{1}$, Wei Wei ${ }^{2}$, Chao Zhang ${ }^{3}$, Min Wang ${ }^{1}$, \\ Wei Zhou ${ }^{1}$, Wen Zeng ${ }^{4}$, Zeming Liu ${ }^{1}$, Liang Guo ${ }^{1}$ \\ ${ }^{1}$ Department of Plastic Surgery, Zhongnan Hospital of Wuhan University, Wuhan, China; ${ }^{2}$ Department of Pediatrics, St. John Hospital and Medical \\ Center, Detroit, MI, USA; ${ }^{3}$ Department of Cardiovascular Surgery, Union Hospital, Tongii Medical College, Huazhong University of Science and \\ Technology, Wuhan, China; ${ }^{4}$ Department of Ophthalmology, Zhongnan Hospital of Wuhan University, Wuhan, China \\ Contributions: (I) Conception and design: L Guo, Z Liu; (II) Administrative support: M Wang; (III) Provision of study materials or patients: W \\ Zhou; (IV) Collection and assembly of data: S Chen, W Wei, C Zhang; (V) Data analysis and interpretation: Q Li, L Zhou, Y Huang, W Zeng; (VI) \\ Manuscript writing: All authors; (VII) Final approval of manuscript: All authors. \\ "These authors contributed equally to this work. \\ Correspondence to: Liang Guo; Zeming Liu. Department of Plastic Surgery, Zhongnan Hospital of Wuhan University, Donghu Load 169, Wuchang \\ District, Wuhan 430071, China. Email: guoliangwhzn@163.com; 6myt@163.com.
}

Background: Differentiated thyroid carcinoma (DTC) is the most common clinical type of thyroid carcinoma. There are rare reports on the synergic effects of the different clinicopathological risk factors on the prognosis of it.

Methods: We retrospectively reviewed data on 86,032 DTC patients from the Surveillance, Epidemiology, and End Results (SEER) database. Univariate and multivariate Cox regression analyses were conducted to evaluate the correlation between clinicopathological factors and the prognosis of DTC. Relative excess risk (RERI) of synergic effect, attributable proportion (AP) of synergic effect, and synergy index (SI) were calculated to assess synergic effects. Kaplan-Meier analyses with log-rank tests was used to plot the survival curve affected by different risk factors.

Results: Histology subtype, lymph node metastasis (LNM) status, and distant metastasis (DM) were independent risk factors for cancer-specific survival (CSS) and all-cause survival (ACS) in the multivariate analysis (all, $\mathrm{P}<0.001$ ). Patients' age at diagnosis, sex, extrathyroidal extension, and radiation also influenced prognosis (all, $\mathrm{P}<0.001)$. The cancer-specific mortality $(\mathrm{CSM})$ and all-cause mortality $(\mathrm{ACM})$ rates per 1,000 person-years were higher in patients with follicular thyroid carcinoma (FTC) and in those with N1 stage and M1 stage disease. Furthermore, we observed a significant synergic effect between histology subtype and N stage, as well as histology subtype and $M$ stage for the CSM of DTC (RERI $=48.806, \mathrm{AP}=0.853, \mathrm{SI}=7.565$; $\mathrm{RERI}=37.889, \mathrm{AP}=0.430, \mathrm{SI}=1.771$, respectively). However, no synergic effect was observed in the case of the N stage and $M$ stage for the CSM of DTC (RERI =7.928, AP =0.084, SI =1.093).

Conclusions: Patients with histology subtype of FTC and N1 stage, histology subtype of FTC and M1 stage had significant additive synergic effects on DTC prognosis for CSM.

Keywords: Differentiated thyroid carcinoma (DTC); prognosis; synergic effect; Surveillance, Epidemiology, and End Results (SEER)

Submitted Feb 25, 2020. Accepted for publication Jun 01, 2020.

doi: $10.21037 /$ gs-20-273

View this article at: http://dx.doi.org/10.21037/gs-20-273 


\section{Introduction}

Thyroid carcinoma is among the most commonly occurring malignancies, which can have a 5 -year survival of over $95 \%$, depending on the stage at diagnosis and treatment plan (1). The incidence of thyroid carcinoma has increased significantly worldwide (2-4), owing to early diagnosis. The mortality is stable at 0.5 per 100,000 persons per year $(5,6)$. The Surveillance, Epidemiology, and End Results (SEER) reported that the mortality associated with the disease increased by an average $0.7 \%$ each year during 2006-2015. The most commonly occurring type of thyroid carcinoma, accounting for more than $90 \%$ of such cases, is differentiated thyroid carcinoma (DTC) (7). DTC originates in the thyroid follicular epithelial cells, and mainly includes two subtypes: papillary thyroid carcinoma (PTC) and follicular thyroid carcinoma (FTC).

At present, the main clinical treatment for DTC is surgery. The prognosis in most DTC patients is good, but about $30 \%$ of these patients experience relapse and metastasis, which could worsen the prognosis (8). Therefore, there is a need to improve the surgical prognosis for this disease. Different scoring systems have been used to determine the prognostic stratification in the assessment of cancer-specific mortality (CSM) risk (9-11). The age, grade, extent, and size (AGES) scoring system includes the age at diagnosis, histologic grade, extrathyroidal extension, distant metastasis (DM), and tumor size (10); the DM, patient age, completeness of resection, local invasion, and tumor size (MACIS) score includes DM, age, completeness of surgical resection, invasion, and tumor size (11); and the age, metastasis, extent, and size (AMES) scoring system includes age, DM, extent, and tumor size (9). The tumor, node, metastasis (TNM) staging system is one of few scoring systems to include lymph node metastasis (LNM) and DM. The modifications proposed in 2015 ATA Guidelines include different histologic subtypes, LNM and DM (12). However, no scoring system to date has included histology subtype, LNM, DM and the synergic effects among the three factors (13). Based on the presence of some risk factors affecting DTC prognosis, patients can be categorized in different risk groups to predict the chance for tumor recurrence or mortality. Such classification can help in creating more precise diagnostic and treatment approaches, and help in defining the prognosis for DTC in any patient.

The purpose of the present study was to determine the significant clinicopathological risk factors associated with DTC prognosis, through the collection of relevant clinical data and exploration of the interaction of relevant independent risk factors on survival outcomes and to evaluate whether histology subtype, LNM, and DM affect DTC prognosis and whether there were synergic effects of these factors on the prognosis of DTC. We present the following article/case in accordance with the STROBE reporting checklist (available at http://dx. doi. org/10. 21037/gs-20-273).

\section{Methods}

\section{Data collection}

We conducted a retrospective cohort study using data from the SEER database, a database containing demographic, clinicopathological, and treatment-related characteristics of cancer patients. The study did not require an ethical review and no informed consent was required because of the publicly available data of this study. Our search included patients with thyroid carcinoma originating from thyroid follicular epithelial cells, from January 2004 to December 2013 were included. All included patients were followedup until December 2013. 13134 Cases with missing or incomplete survival data were excluded, resulting in a total of 86,032 DTC patients who were eligible for the analysis (Figure 1). The following information were extracted: demographic variables including age at diagnosis $(<55$ or $\geq 55$ years), race (white, black, other), and sex (male or female); cancer-related clinicopathological characteristics including $\mathrm{T}$ stage $(\leq 4$ or $>4 \mathrm{~cm}$ ), $\mathrm{N}$ stage (N0 or N1 stage), DM (M0 or M1 stage), multifocality, histology type (PTC or FTC), and extrathyroid extension; and treatment characteristics including radiotherapy (none or refused, radiation beam or radioactive implants, radioisotopes or radiation beam plus isotopes or implants) and surgery (none, lobectomy, subtotal or nearly total thyroidectomy, total thyroidectomy).

\section{Statistical analysis}

The two main outcomes we used to represent prognosis in our study were CSM or cancer-specific survival (CSS) and all-cause mortality (ACM) or overall survival (OS). Cases without data on survival duration or with incomplete follow-up duration data were eliminated from our study.

Quantitative variables were presented as mean \pm standard deviation, while categorical variables were 


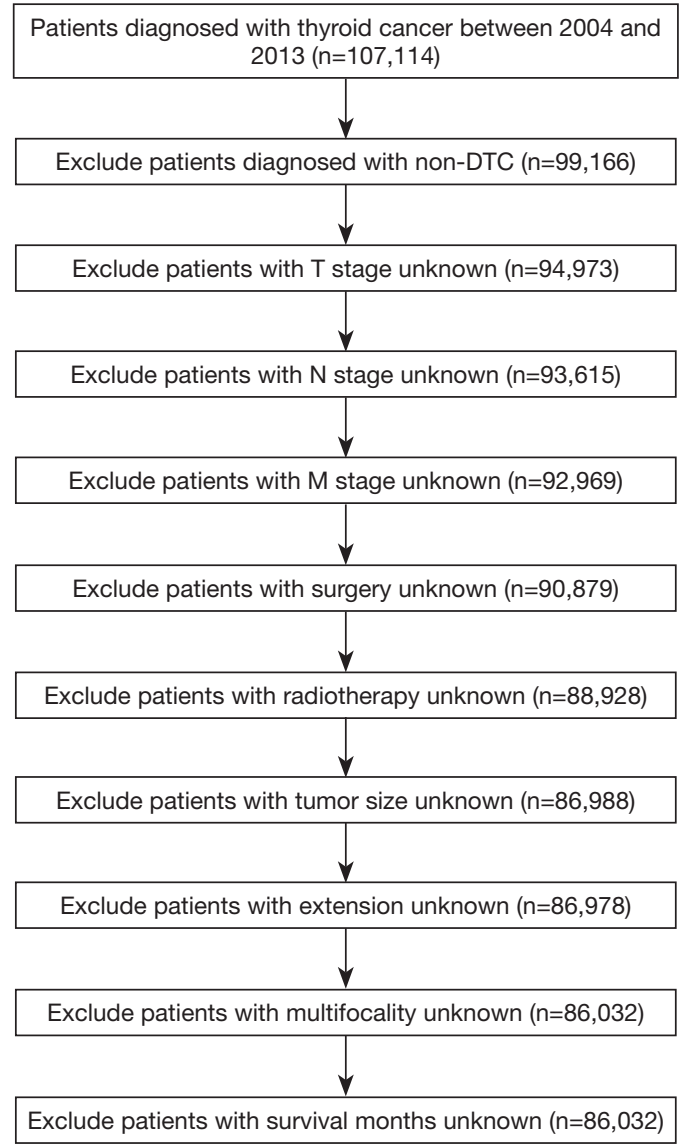

Figure 1 Flow chart of data selection.

presented as percentages. Univariate and multivariate Cox regression analyses were employed to determine any association between CSS and all-cause survival (ACS) and the following variables based on the calculated hazard ratios (HRs) and their 95\% confidence intervals (CIs). These variables were age, year, sex, race, TNM stage, multifocality, tumor type, extrathyroidal extension, radiation, and surgery. Kaplan-Meier analyses with logrank tests were used to determine the association between the variables and the prognosis of DTC after adjustment for confounding factors.

Meanwhile, we calculated the relative excess risk (RERI) of synergic effect, attributable proportion (AP), and synergy index (SI) using $\mathrm{R}$ statistical software to evaluate the synergic effect of histology subtype, LNM and DM on prognosis in DTC. RERI was used to describe the magnitude of the risk due to interaction. The great the absolute value of RERI, the stronger the interaction between factors. If the CI of RERI included 0, there was no interaction between the two factors. AP represented the proportion of disease risk attributable to the interaction of two factors in the presence of both. The greater the absolute value of the AP, the stronger the interaction between the factors. If the $\mathrm{CI}$ of $\mathrm{AP}$ included 0 , there was no interaction between the two factors. When the CI of SI included 1, it meaned there was no additive interaction between two factors. If SI $>1$, it meaned there was a positive interaction between two factors, otherwise, there was a negative additive interaction. All $\mathrm{P}$ values were two-sided, with $\mathrm{P}<0.05$ denoting statistical significance. We used SPSS version 22.0 (IBM Corp., Armonk, NY, USA), R statistical software (R Core Development Team, Vienna, Austria), StataSE 15 software (StataCorp LLC, College Station, TX, USA) and GraphPad Prism version 6 (GraphPad Software Inc., La Jolla, CA, USA) for the statistical analyses.

\section{Results}

\section{General characteristics of the study population}

A total of 86,032 DTC patients were eligible for the study. Overall, the mean age at diagnosis was 49.14 years. Patients under 55 years of age accounted for $63.7 \%$. Between year of 2004 and 2013, there were more patients in the last 5 years $[50,643]$ than that in the previous 5 years $[35,389]$. Among all the patients, Women and whites are the most common. There were more than half of the patients with T1 stage. Twenty-one point seven percent of patients occurred LNM and the overall DM rate was not high (1.0\%). Patients with multifocality account for $40.4 \%$. Eighty-one thousand two hundred and twenty-two (94.4\%) patients were diagnosed with PTC and 4,810 (5.6\%) with FTC; 18,628 (21.7\%) patients had LNM, and 874 (1.0\%) had DM. A significantly larger proportion of patients had PTC than FTC. More than half of the patients $(50.9 \%)$ underwent radiation therapy. The vast majority of patients underwent total thyroidectomy $(82.0 \%)$. The mean of survival months of patients was 49.39 months. The number of CSM was 675 and ACM was 3,387 (Table 1).

\section{Risk factors associated with CSM and ACM in DTC}

Univariate analyses showed that $\mathrm{N}$ stage, DM and histology subtype were significantly associated with CSM, as were age at diagnosis, sex, T stage, extrathyroid extension, radiation, and surgery (Table 2) $(\mathrm{P}<0.05$ for all). Multivariate Cox regression analyses showed that histology subtype (HR 
Table 1 Demographic and clinicopathological characteristics of 86,032 patients with DTC

\begin{tabular}{|c|c|}
\hline Characteristics & Number (\%) \\
\hline \multicolumn{2}{|l|}{ Age at diagnosis (year) } \\
\hline Mean [range] & 49.14 [2-105] \\
\hline$<55$ years & $54,785(63.7)$ \\
\hline$\geq 55$ years & $31,247(36.3)$ \\
\hline \multicolumn{2}{|l|}{ Year of diagnosis } \\
\hline 2004-2008 & $35,389(41.1)$ \\
\hline 2009-2013 & $50,643(58.9)$ \\
\hline \multicolumn{2}{|l|}{ Sex } \\
\hline Female & $66,537(77.3)$ \\
\hline Male & $19,495(22.7)$ \\
\hline \multicolumn{2}{|l|}{ Race } \\
\hline White & $70,568(82.0)$ \\
\hline Black & $5,399(6.3)$ \\
\hline Other & 9,086 (10.6) \\
\hline \multicolumn{2}{|l|}{ T stage } \\
\hline $\mathrm{T} 1$ & $52,049(60.5)$ \\
\hline $\mathrm{T} 2$ & $14,705(17.1)$ \\
\hline T3 & $16,394(19.1)$ \\
\hline $\mathrm{T} 4$ & $2,884(3.4)$ \\
\hline LNM & $18,628(21.7)$ \\
\hline $\mathrm{DM}$ & $874(1.0)$ \\
\hline Multifocality & $34,734(40.4)$ \\
\hline \multicolumn{2}{|l|}{ Histology subtype } \\
\hline PTC & $81,222(94.4)$ \\
\hline FTC & $4,810(5.6)$ \\
\hline Extrathyroidal extension & $13,673(15.9)$ \\
\hline \multicolumn{2}{|l|}{ Radiation therapy } \\
\hline None or refused & $42,209(49.1)$ \\
\hline Radiation beam or Radioactive implants & $1,493(1.7)$ \\
\hline $\begin{array}{l}\text { Radioisotopes or Radiation beam plus } \\
\text { isotopes or implants }\end{array}$ & $42,330(49.2)$ \\
\hline \multicolumn{2}{|l|}{ Surgery } \\
\hline Lobectomy & $12,289(14.3)$ \\
\hline Subtotal or near-total thyroidectomy & $3,187(3.7)$ \\
\hline Total thyroidectomy & $70,556(82.0)$ \\
\hline
\end{tabular}

Table 1 (Continued)
Table 1 (Continued)

\begin{tabular}{lc}
\hline Characteristics & Number (\%) \\
\hline Survival months & \\
Mean [range] & $49.39[0-119]$ \\
CSM & $675(0.78)$ \\
ACM & $3,387(3.94)$ \\
\hline
\end{tabular}

DTC, differentiated thyroid cancer; LNM, lymph node metastasis; DM, distant metastasis; PTC, papillary thyroid cancer; FTC, follicular thyroid cancer; CSM, cancer-specific mortality; ACM, all-cause mortality.

$=1.811 ; 95 \%$ CI: $1.423-2.305, \mathrm{P}<0.001), \mathrm{LNM}(\mathrm{HR}=1.91$; 95\% CI: 1.591-2.293, $\mathrm{P}<0.001)$ and $\mathrm{DM}(\mathrm{HR}=6.403$; 95\% CI: $5.320-7.707, \mathrm{P}<0.001)$ were independent risk factors associated with CSM after adjustment for other confounders (Table 2).

Similarly, for ACM, univariate and multivariate Cox regression analysis indicated that FTC type, positive LNM and $\mathrm{DM}$ (all $\mathrm{P}<0.001)$ were independent risk factors after adjustment for other confounders (Table S1).

\section{CSM and ACM rates per 1,000 person-years}

During the follow-up period, the CSM rates per 1,000 person-years for patients with FTC were 4.247, higher than that with PTC, which was 1.704 (Table 3). Moreover, the rates with $\mathrm{N} 1$ stage were 5.059 , higher than that with $\mathrm{N} 0$ stage which was1.027; while the rates for patients with M1 stage were 66.552 , higher than that with M0 stage, which was 1.318 (Table 3).

During the follow-up period, the ACM rates per 1,000 person-years for patients with FTC were 14.656, higher than that with PTC, which was 9.057, for patients N1 stage were 12.888 , higher than that with N0 stage, which was 8.494; rates for patients M1 stage were 99.316, higher than that with M0 stage, which was 8.648 (Table 3). Among the three different variables of histology subtype, $\mathrm{N}$ stage and $M$ stage, we pairwise combined different subgroups of any two different variables to analyze the CSM and ACM rates per 1,000 person-years for patients, the results were consistent (Table 3).

\section{Synergic effects of histology subtype, LNM, and DM on DTC-related prognosis}

To investigate the interaction of histology subtype, $\mathrm{N}$ 
Table 2 Clinicopathological parameters associated with the CSM

\begin{tabular}{|c|c|c|c|c|c|c|}
\hline Parameters & \multicolumn{3}{|c|}{ Univariate } & \multicolumn{3}{|c|}{ Multivariate } \\
\hline \multicolumn{7}{|c|}{ Age of diagnosis } \\
\hline$<55$ & Ref & & & Ref & & \\
\hline$\geq 55$ & 8.468 & $6.964-10.297$ & $<0.001^{*}$ & 1.066 & $1.060-1.072$ & $<0.001^{*}$ \\
\hline 2004-2008 & Ref & & & Ref & & \\
\hline 2009-2013 & 0.790 & $0.664-0.941$ & $0.008^{*}$ & 0.858 & $0.721-1.021$ & 0.084 \\
\hline \multicolumn{7}{|l|}{ Sex } \\
\hline Female & Ref & & & Ref & & \\
\hline White & Ref & & & Ref & & \\
\hline Black & 0.806 & $0.567-1.145$ & 0.228 & 1.024 & $0.716-1.465$ & 0.895 \\
\hline Other & 1.381 & $1.110-1.719$ & $0.004^{*}$ & 0.956 & $0.766-1.192$ & 0.688 \\
\hline \multicolumn{7}{|l|}{ T stage } \\
\hline $\mathrm{T} 1$ & Ref & & & Ref & & \\
\hline $\mathrm{T} 2$ & 2.666 & $1.890-3.759$ & $<0.001^{*}$ & 2.423 & $1.707-3.440$ & $<0.001^{\star}$ \\
\hline T3 & 8.638 & $6.615-11.280$ & $<0.001^{*}$ & 4.474 & $3.138-6.379$ & $<0.001^{\star}$ \\
\hline $\mathrm{T} 4$ & 83.701 & $65.110-107.599$ & $<0.001^{*}$ & 17.005 & $11.403-25.361$ & $<0.001^{\star}$ \\
\hline \multicolumn{7}{|l|}{$\mathrm{N}$ stage } \\
\hline Mo & Ref & & & Ref & & \\
\hline M1 & 48.518 & $41.115-57.253$ & $<0.001^{*}$ & 6.403 & $5.320-7.707$ & $<0.001^{\star}$ \\
\hline \multicolumn{7}{|l|}{ Multifocality } \\
\hline Yes & Ref & & & Ref & & \\
\hline No & 1.044 & $0.896-1.217$ & 0.582 & 0.793 & $0.677-0.929$ & $0.004^{*}$ \\
\hline \multicolumn{7}{|l|}{ Histology types } \\
\hline Papillary & Ref & & & Ref & & \\
\hline Follicular & 2.620 & $2.111-3.252$ & $<0.001^{*}$ & 1.811 & $1.423-2.305$ & $<0.001^{*}$ \\
\hline \multicolumn{7}{|c|}{ Extrathyroidal extension } \\
\hline No & Ref & & & Ref & & \\
\hline Yes & 13.363 & $11.308-15.791$ & $<0.001^{*}$ & 1.388 & $1.024-1.883$ & $0.035^{\star}$ \\
\hline
\end{tabular}

Table 2 (Continued) 
Table 2 (Continued)

\begin{tabular}{|c|c|c|c|c|c|c|}
\hline Parameters & \multicolumn{3}{|c|}{ Univariate } & \multicolumn{3}{|c|}{ Multivariate } \\
\hline \multicolumn{7}{|l|}{ Radiation } \\
\hline None or refused & Ref & & & Ref & & \\
\hline $\begin{array}{l}\text { Radiation beam or radioactive } \\
\text { implants }\end{array}$ & 19.730 & $15.905-24.473$ & $<0.001^{*}$ & 2.953 & $2.337-3.732$ & $<0.001^{*}$ \\
\hline \multicolumn{7}{|l|}{ Surgery } \\
\hline Lobectomy & Ref & & & Ref & & \\
\hline
\end{tabular}

*, $\mathrm{P}<0.05$. CSM, cancer-specific mortality; HR, hazard ratio; $\mathrm{Cl}$, confidence interval.

status and DM on DTC prognosis in-depth, patients were grouped into three categories, namely histology subtype and $\mathrm{N}$ stage, histology subtype and $\mathrm{M}$ stage, $\mathrm{N}$ stage and $M$ stage. Each category was then further divided into four subgroups.

In terms of histology subtype and $\mathrm{N}$ stage combinations, the probability of CSM was the greatest in those with FTC and $\mathrm{N} 1$ stage ( $\mathrm{HR}=3.800$; 95\% CI: 2.476-5.831, $\mathrm{P}<0.001$ ), compared to cases with the other three combinations, after adjustment for confounders (Table 4). We also found that the probability of CSM in DTC was greater in patients with $\mathrm{PTC}$ and $\mathrm{N} 1$ stage disease $(\mathrm{HR}=1.872 ; 95 \% \mathrm{CI}$ : 1.549-2.261, $\mathrm{P}<0.001)$ or FTC only (HR $=1.854 ; 95 \%$ CI: 1.396-2.463, $\mathrm{P}<0.001)$ compared to cases with PTC and N0 stage, after adjustment for confounders (Table 4). Based on the results of the abovementioned statistical analysis, the RERI was 48.806. The AP was 0.853. Additionally, the SI was 7.565 (Table 4). Hence, we concluded that a synergic effect between FTC and N1 stage on CSM exists. Similar results were recorded for ACM (Table S2).

In terms of histology subtype and $M$ stage combinations, the probability of CSM was the greatest in patients with FTC and M1 stage disease (HR $=14.163 ; 95 \% \mathrm{CI}$ : 10.418-19.254, $\mathrm{P}<0.001)$ compared to those with other combinations, after adjustment for other confounders. The probability of CSM was greater in patients with PTC and M1 or FTC alone compared to those with PTC and
M0 stage after adjustment for confounders. Based on the abovementioned results, the RERI was 37.889. The AP was 0.430 . Moreover, the SI was 1.771 . The aforementioned results indicated that a significant synergic effect between histology subtype of FTC and M1 stage on CSM exists (Table 4). However, in terms of ACS, there was no synergic effect between histology subtype and $M$ stage on ACM (Table S2).

Similarly, we calculated and compared the RERI, AP and SI values between cases with different $\mathrm{N}$ stages and $\mathrm{M}$ stages to determine CSM (Table 4) and ACM (Table S2). The $95 \%$ CIs for RERI and AP contained ' 0 ' and that for SI contained ' 1 ', either for CSM or ACM. Therefore, we concluded that there was no interaction between $\mathrm{N}$ stage and $M$ stage.

\section{Kaplan-Meier analysis of survival in DTCs}

Based on the Kaplan-Meier analysis of the four-histology subtype and N status groups, the CSS and ACS rates were relatively flat when comparing patients with PTC and N0 stage disease and those with FTC and N0 stage disease (both $\mathrm{P}<0.001$, Figure $2 A$ ). In patients with $\mathrm{PTC}$ and $\mathrm{N} 1$ stage disease, a modest decline in the CSS curve was observed, while in those with FTC and N1 stage disease, a sharp decline was noted in the CSS curve. Similar results were obtained in those with PTC and N0 stage and FTC and 
Table 3 CSM (per 1,000 person-years) and ACM (per 1,000 person-years) of relevant factors and combined factors for DTC

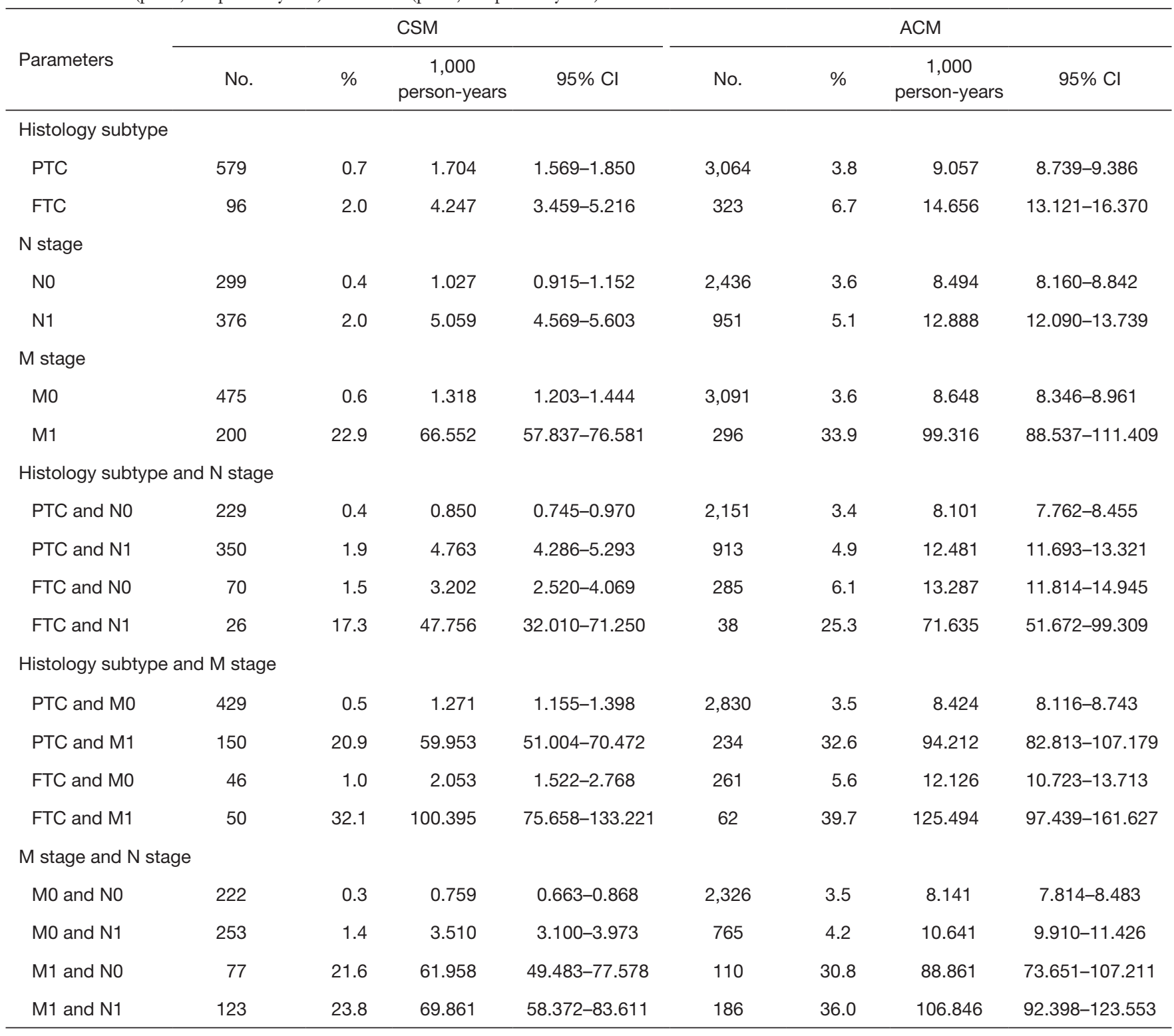

CSM, cancer-specific mortality; ACM, all-cause mortality; DTC, differentiated thyroid cancer; Cl, confidence interval; PTC, papillary thyroid cancer; FTC, follicular thyroid cancer.

N1 stage combinations in the analysis for ACS (Figure 2B). However, the ACS curve for cases with FTC and N0 stage combination declined more rapidly than that in cases with PTC and N1 stage combination.

In addition, according to the Kaplan-Meier analysis of the four groups divided by histology subtype and $M$ status, the CSS and ACS curves for DTC patients with PTC and M0 stage, FTC and M0 stage, and PTC and M1 showed sharp declines; however, the CSS and ACS curves in those with FTC and M1 stage combination declined more rapidly (Figure $3 A, B)$. Similar results were observed in the KaplanMeier analysis for the four groups divided by $\mathrm{N}$ status and $M$ status. Both the CSS and ACS curves showed faster declines in those with DM than in those without DM, regardless of the presence or absence of $\mathrm{LNM}(\mathrm{P}<0.001$ for all, Figure $4 A, B)$. 
Table 4 Measures for estimation of synergic effect between different risk factors for the CSM of DTC

\begin{tabular}{|c|c|c|c|c|c|c|c|}
\hline Parameters & $\begin{array}{l}\text { Death events } \\
(\%)\end{array}$ & $\begin{array}{l}\text { Total case } \\
\text { (n) }\end{array}$ & $\mathrm{HR}(95 \% \mathrm{Cl})$ & $P$ value & RERI (95\% Cl) & AP $(95 \% \mathrm{Cl})$ & $\mathrm{SI}(95 \% \mathrm{Cl})$ \\
\hline \multicolumn{8}{|c|}{ Histology subtype and N stage } \\
\hline PTC and N1 & $350(1.9)$ & 18,478 & $1.872(1.549-2.261)$ & $<0.001^{*}$ & $\begin{array}{c}48.806 \\
(23.799-73.813)\end{array}$ & $\begin{array}{c}0.853 \\
(0.787-0.918)\end{array}$ & $\begin{array}{c}7.565 \\
(4.788-11.954)\end{array}$ \\
\hline \multicolumn{8}{|c|}{ Histology subtype and M stage } \\
\hline PTC and MO & $429(0.5)$ & 80,504 & Ref & & \multirow{2}{*}{$\begin{array}{c}37.889 \\
(6.781-68.997)\end{array}$} & \multirow{2}{*}{$\begin{array}{c}0.430 \\
(0.214-0.647)\end{array}$} & \multirow{2}{*}{$\begin{array}{c}1.771 \\
(1.205-2.603)\end{array}$} \\
\hline PTC and M1 & $150(20.9)$ & 718 & $6.009(4.904-7.364)$ & $<0.001^{*}$ & & & \\
\hline $\mathrm{MO}$ and NO & $222(0.3)$ & 67,047 & Ref & & \multirow{4}{*}{$\begin{array}{c}7.928 \\
(-20.336-36.192)\end{array}$} & \multirow{4}{*}{$\begin{array}{c}0.084 \\
(-0.205-0.374)\end{array}$} & \multirow{4}{*}{$\begin{array}{c}1.093 \\
(0.794-1.505)\end{array}$} \\
\hline $\mathrm{M} 0$ and $\mathrm{N} 1$ & $253(1.4)$ & 18,111 & 2.418 (1.968-2.970) & $<0.001^{*}$ & & & \\
\hline M1 and N0 & 77 (21.6) & 357 & $11.359(8.543-15.103)$ & $<0.001^{*}$ & & & \\
\hline $\mathrm{M} 1$ and $\mathrm{N} 1$ & $123(23.8)$ & 517 & $11.736(9.080-15.169)$ & $<0.001^{*}$ & & & \\
\hline
\end{tabular}

Adjusted for age at diagnosis, year at diagnosis, sex, race, T stage, $\mathrm{N}$ stage, $\mathrm{M}$ stage, multifocality, extrathyroidal extension, radiation, surgery. * $\mathrm{P}<0.05$. CSM, cancer-specific mortality; DTC, differentiated thyroid cancer; n, number; HR, hazard ratio; Cl, confidence interval; RERI, relative excess risk; AP, attributable proportion; SI, synergy index; PTC, papillary thyroid cancer; FTC, follicular thyroid cancer.

A

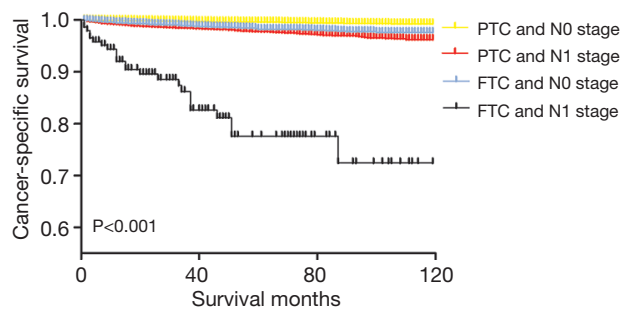

B

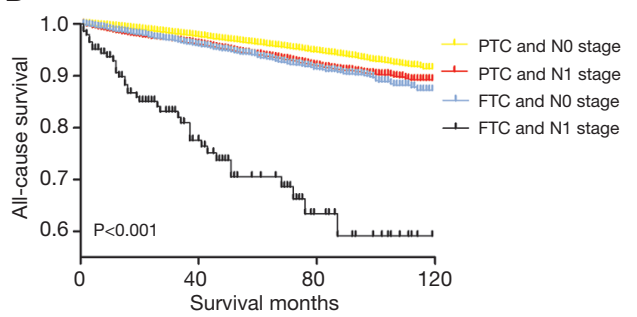

Figure 2 Survival in lymph lode metastasis and DTC patients. (A) Effects of histology subtype and N stage on CSS of patients with DTC; (B) effects of histology subtype and N stage on ACS of patients with DTC. CSS, cancer-specific survival; DTC, differentiated thyroid cancer; ACS, all-cause survival; PTC, papillary thyroid cancer; FTC, follicular thyroid cancer.

\section{Discussion}

Many studies had reported risk factors associated with DTC death. However, the relationship between risk factors and tumor-related mortality remains to be clarified for DTC. In the present study, we divided DTC patients into subgroups of PTC, FTC, N0 stage, N1 stage, M0 stage and M1 stage to evaluate differences in their clinicopathologic features and oncological outcomes. According to the multivariate regression analysis, we found that histology subtype, $\mathrm{N}$ stage and $M$ stage were associated with a mortality due to both cancer-specific and all-cancer reasons, which is consistent with the findings in previous reports $(12,14)$, the Kaplan-Meier analysis of survival of DTCs confirmed our findings again.

Studies have shown that PTC patients have a better 

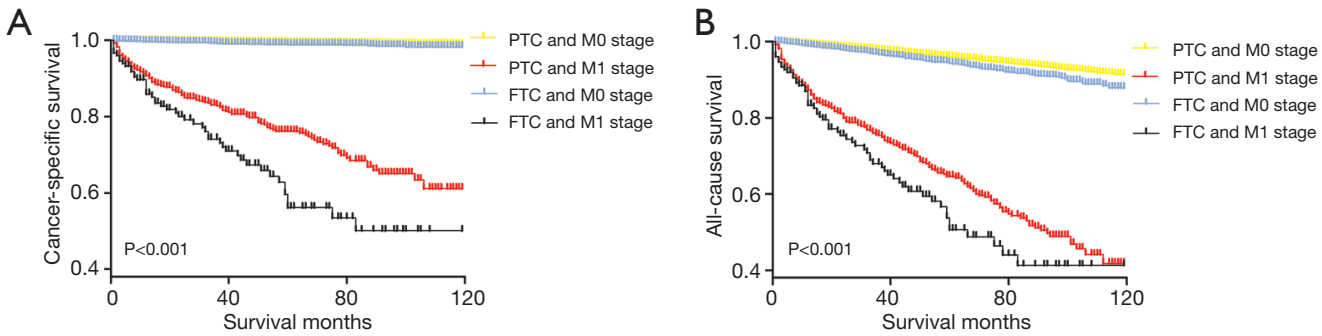

Figure 3 Survival in distant metastasis and DTC patients. (A) Effects of histology subtype and M stage on CSS of patients with DTC; (B) effects of histology subtype and M stage on ACS of patients with DTC. DTC, differentiated thyroid cancer; CSS, cancer-specific survival; ACS, all-cause survival.

A

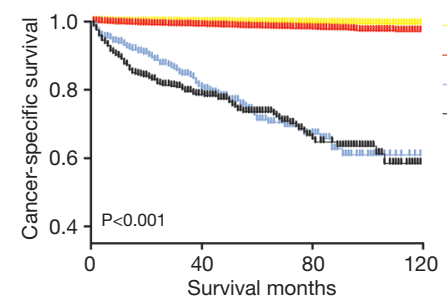

B

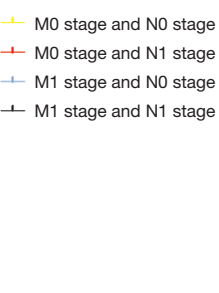

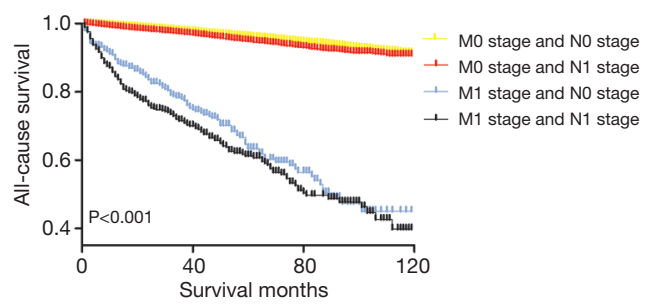

Figure 4 Survival in lymph lode metastasis and distant metastasis with DTC patients. (A) Effects of N stage and M stage on CSS of patients with DTC; (B) effects of $\mathrm{N}$ stage and $\mathrm{M}$ stage on ACS of patients with DTC. DTC, differentiated thyroid cancer; CSS, cancer-specific survival; ACS, all-cause survival.

prognosis than FTC patients (15-17). Lundgren's study indicated that different histology subtypes could affect DTC prognosis; more specifically, patients with FTC had a risk of death several times higher than patients with PTC (18). Our research showed that the rate of CSM and ACM per 1,000 person-year for patients with FTC was higher than that for patients with PTC (Table 1).

Although the influence of LNM on the prognosis of thyroid cancer remains controversial, previous studies have reported that while LNM may affect recurrence in thyroid cancer, it does not affect survival $(19,20)$. For both the seventh edition and eighth editions of AJCC TNM classification system, multivariate analyses have demonstrated that the presence of cervical LNM did not predict worse survival (4). Besides, not all large casecontrol studies have suggested that LNM was among the primary factors associated with higher morbidity for thyroid cancer (18). Vuong et al. (21) reported that male sex, vascular invasion, extrathyroid extension, and LNM were independent risk factors for DTC. In our study, univariate analyses showed that age at diagnosis, sex, T stage, extrathyroid extension, radiation, surgery, $\mathrm{N}$ status, DM, and histology type were predictive risk factors for CSS in DTC. Particularly, we found that the presence of a positive $\mathrm{N}$ stage $(\mathrm{P}<0.001)$ led to worse CSS, similar to the findings of Suman et al. (22).

While DM does not commonly occur in DTC, it adversely impacts mortality. In this study, we found that the incidence of DM in DTC was $1.0 \%$, and the CSM rate in patients with DM was 48.518 times higher than that in patients without DM. DM as a prognostic factor for CSM in patients with DTC has been widely studied (21,23-25). The 10 -year OS rate associated with DTC is $85-93 \%$; however, if DM occurs the 5 -year OS rate may drop to $50 \%(26,27)$. A recent study concluded that the presence of bone metastases in DTC was associated with lower OS (28), consistent with our findings.

DM is more commonly seen with FTC than PTC. In PTC, DM is predominantly confined to the lung tissue, while in FTC extrapulmonary metastases were more common and the incidence of bone metastasis was significantly higher than that for PTC (7-20\% vs. $1-7 \%$ ) (29). A previous study reported that the prognosis of thyroid cancer patients with simple pulmonary metastasis 
was better than those with extrapulmonary metastasis. This was because the $\mathrm{I}^{131}$ radiation sensitivity in patients with pulmonary metastasis was reportedly higher than that in those with bone metastases (16) resulting in a better prognosis for patients with PTC than those with FTC. This was consistent with our findings. On the other hand, studies had shown different molecular profiles of tumor that metastasized to different organs leaded to different prognosis $(30,31)$. Therefore, it can be further speculated that the association between histology type and prognosis in DTC, may be caused by the different molecular profiles between FTC and PTC, which may affect the site of DM. Further studies on the molecular profile of DTC need to be conducted to confirm the aforementioned findings.

To the best of our knowledge, no study to date has focused on the possibility of a synergic effect between clinicopathological characteristics and prognosis in DTC. In the present study, we divided each of the three risk factors (histology subtype, $\mathrm{N}$ status and $\mathrm{M}$ stage) into two subgroups, and then every four subgroups of two risk factors were paired for the calculation of RERI, AP and SI to assess the additive interaction among the three risk factors. We found that, except for the $\mathrm{N}$ stage and $\mathrm{M}$ stage combinations, the other two combinations (histology subtype of FTC and N1 stage, histology subtype of FTC and M1 stage) had a significant synergic effect on DTC prognosis for CSM. Our study suggested that histology subtype and $\mathrm{N}$ stage had a synergic effect on the prognosis of DTC as did histology subtype and M stage for CSM. In other words, patients with FTC and LNM or DM had a higher rate of CSM than those with one or no risk factor. However, no significant increases in CSM rate were observed in the presence of LNM and DM. Existing risk stratification systems are tightly based on the impact of individual risk factors on tumor prognosis, we investigated whether there were synergic effects between some risk factors, which could lead to a more accurate rating of risk stratification. Based on the results, FTC patients with LNM or DM can be directly classified as high-risk. This may add some credibility to the current risk stratification system and may provide some references for clinical treatment of thyroid cancer. For DTC patients with signs of LNM and DM preoperative, our findings may have some implications for them, including potential changes in surgical procedures and potential radiation therapy may be required.

This study has some limitations. First, the SEER database lacks detailed information on recurrence and surgery-related complications of DTC, so these factors could not be considered. Second, we did not assess or consider the patients' family history, vascular invasion, or other histology characteristics. Third, there were no information on whether patients underwent surgery more than once in the SEER database, leading to possible result bias. Fourth, the lack of information on the histological subtypes of PTC and FTC leaded our results incomplete. Fifth, another important limitation was the absence of data on the location of metastases (lung, bone, others), as well as the chronology of distant metastases (synchronous, metachronous). Fifth, the SEER database does not record the exact radioiodine doses and the total cumulative activity of radioiodine of a patient received. The number of radioiodine doses received and the total cumulative activity of radioiodine are important prognostic factors that should be taken into account.

\section{Conclusions}

In conclusion, our results indicated that histology subtype, LNM, and DM are associated with higher CSM and ACM rates in DTC. Moreover, the histology subtype and N status as well as the histology subtype and $M$ status combinations have a synergic effect in significantly increasing the mortality rate in DTC. Detailed reports on these risk factors may provide a more accurate risk stratification assessment of DTC for better treatment.

\section{Acknowledgments}

Funding: None.

\section{Footnote}

Reporting Checklist: The authors have completed the STROBE reporting checklist. Available at http://dx. doi. org/10. 21037/gs-20-273

Peer Review File: Available at http://dx. doi. org/10.21037/ gs-20-273

Conflicts of Interest: All authors have completed the ICMJE uniform disclosure form (available at http://dx. doi. org/10. 21037/gs-20-273). The authors have no conflicts of interest to declare.

Ethical statement: The authors are accountable for all aspects of the work in ensuring that questions related 
to the accuracy or integrity of any part of the work are appropriately investigated and resolved. The study did not require an ethical review and no informed consent was required because of the publicly available data of this study.

Open Access Statement: This is an Open Access article distributed in accordance with the Creative Commons Attribution-NonCommercial-NoDerivs 4.0 International License (CC BY-NC-ND 4.0), which permits the noncommercial replication and distribution of the article with the strict proviso that no changes or edits are made and the original work is properly cited (including links to both the formal publication through the relevant DOI and the license). See: https://creativecommons.org/licenses/by-nc-nd/4.0/.

\section{References}

1. Cabanillas ME, McFadden DG, Durante C. Thyroid cancer. Lancet 2016;388:2783-95.

2. Brito JP, Al Nofal A, Montori VM, et al. The impact of subclinical disease and mechanism of detection on the rise in thyroid cancer incidence: a population-based study in Olmsted County, Minnesota during 1935 through 2012. Thyroid 2015;25:999-1007.

3. Viola D, Valerio L, Molinaro E, et al. Treatment of advanced thyroid cancer with targeted therapies: ten years of experience. Endocr Relat Cancer 2016;23:R185-205.

4. Tam S, Boonsripitayanon M, Amit M, et al. Survival in differentiated thyroid cancer: comparing the AJCC cancer staging seventh and eighth editions. Thyroid 2018;28:1301-10.

5. Pellegriti G, Frasca F, Regalbuto C, et al. Worldwide increasing incidence of thyroid cancer: update on epidemiology and risk factors. J Cancer Epidemiol 2013;2013:965212.

6. Kitahara CM, Sosa JA. The changing incidence of thyroid cancer. Nat Rev Endocrinol 2016;12:646-53.

7. Sherman SI. Thyroid carcinoma. Lancet 2003;361:501-11.

8. Venkat R, Guerrero MA. Recent advances in the surgical treatment of differentiated thyroid cancer: a comprehensive review. ScientificWorldJournal 2013;2013:425136.

9. Cady B, Rossi R. An expanded view of risk-group definition in differentiated thyroid carcinoma. Surgery 1988;104:947-53.

10. Hay ID. Papillary thyroid carcinoma. Endocrinol Metab Clin North Am 1990;19:545-76.

11. Hay ID, Bergstralh EJ, Goellner JR, et al. Predicting outcome in papillary thyroid carcinoma: development of a reliable prognostic scoring system in a cohort of 1779 patients surgically treated at one institution during 1940 through 1989. Surgery 1993;114:1050-8.

12. Haugen BR, Alexander EK, Bible KC, et al. 2015 American Thyroid Association Management guidelines for adult patients with thyroid nodules and differentiated thyroid cancer: the American Thyroid Association Guidelines Task Force on Thyroid Nodules and Differentiated Thyroid Cancer. Thyroid 2016;26:1050-7.

13. Sobin LH. TNM, sixth edition: new developments in general concepts and rules. Semin Surg Oncol 2003;21:19-22.

14. Wang F, Yu X, Shen X, et al. The prognostic value of tumor multifocality in clinical outcomes of papillary thyroid cancer. J Clin Endocrinol Metab 2017;102:3241-50.

15. Simpson WJ, McKinney SE, Carruthers JS, et al. Papillary and follicular thyroid cancer. Prognostic factors in 1,578 patients. Am J Med 1987;83:479-88.

16. Schlumberger $M$, Challeton $C$, De Vathaire F, et al. Radioactive iodine treatment and external radiotherapy for lung and bone metastases from thyroid carcinoma. J Nucl Med 1996;37:598-605.

17. Nixon IJ, Whitcher MM, Palmer FL, et al. The impact of distant metastases at presentation on prognosis in patients with differentiated carcinoma of the thyroid gland. Thyroid 2012;22:884-9.

18. Lundgren CI, Hall P, Dickman PW, et al. Clinically significant prognostic factors for differentiated thyroid carcinoma: a population-based, nested case-control study. Cancer 2006;106:524-31.

19. White ML, Gauger PG, Doherty GM. Central lymph node dissection in differentiated thyroid cancer. World $\mathbf{J}$ Surg 2007;31:895-904.

20. Ito Y, Miyauchi A, Masuoka H, et al. Excellent prognosis of central lymph node recurrence-free survival for $\mathrm{cNOM} 0$ papillary thyroid carcinoma patients who underwent routine prophylactic central node dissection. World J Surg 2018;42:2462-8.

21. Vuong HG, Duong UNP, Pham TQ, et al. Clinicopathological risk factors for distant metastasis in differentiated thyroid carcinoma: a meta-analysis. World J Surg 2018;42:1005-17.

22. Suman P, Wang CH, Abadin SS, et al. Risk factors for central lymph node metastasis in papillary thyroid carcinoma: a National Cancer Data Base (NCDB) study. Surgery 2016;159:31-39.

23. Lang BH, Wong KP, Cheung CY, et al. Evaluating the 
prognostic factors associated with cancer-specific survival of differentiated thyroid carcinoma presenting with distant metastasis. Ann Surg Oncol 2013;20:1329-35.

24. Eustatia-Rutten CF, Corssmit EP, Biermasz NR, et al. Survival and death causes in differentiated thyroid carcinoma. J Clin Endocrinol Metab 2006;91:313-9.

25. Durante C, Haddy N, Baudin E, et al. Long-term outcome of 444 patients with distant metastases from papillary and follicular thyroid carcinoma: benefits and limits of radioiodine therapy. J Clin Endocrinol Metab 2006;91:2892-9.

26. Ruegemer JJ, Hay ID, Bergstralh EJ, et al. Distant metastases in differentiated thyroid carcinoma: a multivariate analysis of prognostic variables. J Clin Endocrinol Metab 1988;67:501-8.

Cite this article as: Zhou L, Li Q, Chen S, Huang Y, Wei W, Zhang C, Wang M, Zhou W, Zeng W, Liu Z, Guo L. Synergic effects of histology subtype, lymph node metastasis, and distant metastasis on prognosis in differentiated thyroid carcinoma using the SEER database. Gland Surg 2020;9(4):907-918. doi: $10.21037 /$ gs-20-273
27. Hundahl SA, Fleming ID, Fremgen AM, et al. A National Cancer Data Base report on 53,856 cases of thyroid carcinoma treated in the U.S., 1985-1995 [see commetns]. Cancer 1998;83:2638-48.

28. Califano I, Deutsch S, Löwenstein A, et al. Outcomes of patients with bone metastases from differentiated thyroid cancer. Arch Endocrinol Metab 2018;62:14-20.

29. Wexler JA. Approach to the thyroid cancer patient with bone metastases. J Clin Endocrinol Metab 2011;96:2296-307.

30. Nguyen DX, Massagué J. Genetic determinants of cancer metastasis. Nat Rev Genet 2007;8:341-52.

31. Nguyen DX, Bos PD, Massagué J. Metastasis: from dissemination to organ-specific colonization. Nat Rev Cancer 2009;9:274-84. 
Table S1 Clinicopathological parameters associated with the ACS

\begin{tabular}{|c|c|c|c|c|c|c|}
\hline \multirow{2}{*}{ Parameters } & \multicolumn{3}{|c|}{ Univariate } & \multicolumn{3}{|c|}{ Multivariate } \\
\hline & $\mathrm{HR}$ & $95 \% \mathrm{Cl}$ & $\mathrm{P}$ value & $\mathrm{HR}$ & $95 \% \mathrm{Cl}$ & $P$ value \\
\hline \multicolumn{7}{|l|}{ Age of diagnosis } \\
\hline$<55$ & Ref & & & Ref & & \\
\hline$\geq 55$ & 6.848 & $6.313-7.428$ & $<0.001^{*}$ & 5.794 & $5.331-6.296$ & $<0.001^{*}$ \\
\hline \multicolumn{7}{|l|}{ Year at diagnosis } \\
\hline 2004-2008 & Ref & & & Ref & & \\
\hline 2009-2013 & 0.949 & $0.873-1.031$ & 0.215 & 0.929 & $0.855-1.009$ & 0.082 \\
\hline \multicolumn{7}{|l|}{ Sex } \\
\hline Female & Ref & & & Ref & & \\
\hline Male & 2.395 & $2.237-2.565$ & $<0.001^{*}$ & 1.669 & $1.555-1.792$ & $<0.001^{*}$ \\
\hline \multicolumn{7}{|l|}{ Race } \\
\hline White & Ref & & & Ref & & \\
\hline Black & 1.229 & $1.082-1.396$ & $0.002^{*}$ & 1.276 & $1.122-1.452$ & $<0.001^{*}$ \\
\hline Other & 0.844 & $0.748-0.952$ & $0.006^{*}$ & 0.795 & $0.704-0.897$ & $<0.001^{*}$ \\
\hline \multicolumn{7}{|l|}{ T stage } \\
\hline $\mathrm{T} 1$ & Ref & & & Ref & & \\
\hline $\mathrm{T} 2$ & 1.013 & $0.914-1.123$ & 0.800 & 1.136 & $1.020-1.264$ & $0.020^{\star}$ \\
\hline T3 & 1.576 & $1.446-1.718$ & $<0.001^{*}$ & 1.353 & $1.181-1.550$ & $<0.001^{*}$ \\
\hline T4 & 6.531 & $5.935-7.186$ & $<0.001^{*}$ & 3.414 & $2.852-4.088$ & $<0.001^{*}$ \\
\hline \multicolumn{7}{|l|}{ N stage } \\
\hline NO & Ref & & & Ref & & \\
\hline N1 & 1.510 & $1.401-1.628$ & $<0.001^{*}$ & 1.374 & $1.255-1.503$ & $<0.001^{*}$ \\
\hline \multicolumn{7}{|l|}{ M stage } \\
\hline MO & Ref & & & Ref & & \\
\hline M1 & 11.590 & $10.286-13.059$ & $<0.001^{*}$ & 4.069 & $3.568-4.641$ & $<0.001^{*}$ \\
\hline \multicolumn{7}{|l|}{ Multifocality } \\
\hline Yes & Ref & & & Ref & & \\
\hline No & 0.977 & $0.912-1.046$ & 0.503 & .951 & $0.885-1.022$ & 0.173 \\
\hline \multicolumn{7}{|l|}{ Histology type } \\
\hline Papillary & Ref & & & Ref & & \\
\hline Follicular & 1.630 & $1.454-1.829$ & $<0.001^{*}$ & 1.327 & $1.170-1.505$ & $<0.001^{*}$ \\
\hline \multicolumn{7}{|l|}{ Extrathyroidal extension } \\
\hline No & Ref & & & Ref & & \\
\hline Yes & 2.466 & $2.294-2.652$ & $<0.001^{*}$ & 1.097 & $0.943-1.277$ & 0.228 \\
\hline \multicolumn{7}{|l|}{ Radiation } \\
\hline None or refused & Ref & & & Ref & & \\
\hline $\begin{array}{l}\text { Radiation beam or } \\
\text { radioactive implants }\end{array}$ & 3.188 & $2.765-3.675$ & $<0.001^{*}$ & 1.492 & $1.281-1.737$ & $<0.001^{*}$ \\
\hline $\begin{array}{l}\text { Radioisotopes or } \\
\text { radiation beam plus } \\
\text { isotopes or implants }\end{array}$ & 0.746 & $0.696-0.800$ & $<0.001^{*}$ & 0.642 & $0.595-0.694$ & $<0.001^{*}$ \\
\hline \multicolumn{7}{|l|}{ Surgery } \\
\hline Lobectomy & Ref & & & Ref & & \\
\hline $\begin{array}{l}\text { Subtotal or near total } \\
\text { thyroidectomy }\end{array}$ & 1.053 & $0.890-1.245$ & 0.548 & 1.035 & $0.874-1.226$ & 0.692 \\
\hline Total thyroidectomy & 0.865 & $0.789-0.947$ & $0.002^{*}$ & 0.918 & $0.832-1.012$ & 0.084 \\
\hline
\end{tabular}

*, $\mathrm{P}<0.05$. ACS, all-cause survival; $\mathrm{HR}$, hazard ratio; $\mathrm{Cl}$, confidence interval. 
Table S2 Measures for estimation of synergic effect between different risk factors for the ACM of DTC

\begin{tabular}{|c|c|c|c|c|c|c|c|}
\hline Parameters & $\begin{array}{c}\text { Death events } \\
(\%)\end{array}$ & $\begin{array}{l}\text { Total case } \\
\text { (n) }\end{array}$ & $\mathrm{HR}(95 \% \mathrm{Cl})$ & $P$ value & RERI (95\% Cl) & AP $(95 \% \mathrm{Cl})$ & $\mathrm{SI}(95 \% \mathrm{Cl})$ \\
\hline \multicolumn{8}{|c|}{ Histology subtype and N stage } \\
\hline PTC and N1 & $913(4.9)$ & 18,478 & $1.342(1.227-1.468)$ & $<0.001^{*}$ & $\begin{array}{c}7.258 \\
(3.723-10.794)\end{array}$ & $\begin{array}{c}0.759 \\
(0.667-0.852)\end{array}$ & $\begin{array}{c}0.759 \\
(0.667-0.852)\end{array}$ \\
\hline \multicolumn{8}{|c|}{ Histology subtype and M stage } \\
\hline PTC and MO & $2,830(3.5)$ & 80,504 & Ref & & \multirow{2}{*}{$\begin{array}{c}4.203 \\
(-1.965-10.371)\end{array}$} & \multirow{2}{*}{$\begin{array}{c}0.232 \\
(-0.040-0.504)\end{array}$} & \multirow{2}{*}{$\begin{array}{c}1.326 \\
(0.910-1.931)\end{array}$} \\
\hline PTC and M1 & $234(32.6)$ & 718 & $3.950(3.417-4.565)$ & $<0.001^{*}$ & & & \\
\hline \multicolumn{8}{|c|}{$\mathrm{M}$ stage and $\mathrm{N}$ stage } \\
\hline $\mathrm{MO}$ and NO & $2,326(3.5)$ & 67,047 & Ref & & \multirow{4}{*}{$\begin{array}{c}3.017 \\
(-0.940-6.973)\end{array}$} & \multirow{4}{*}{$\begin{array}{c}0.193 \\
(-0.037-0.423)\end{array}$} & \multirow{4}{*}{$\begin{array}{c}1.260 \\
(0.927-1.712)\end{array}$} \\
\hline $\mathrm{M} 0$ and $\mathrm{N} 1$ & $765(4.2)$ & 18,111 & $1.375(1.253-1.508)$ & $<0.001^{*}$ & & & \\
\hline M1 and N0 & $110(30.8)$ & 357 & $4.271(3.496-5.218)$ & $<0.001^{*}$ & & & \\
\hline $\mathrm{M} 1$ and N1 & $186(36.0)$ & 517 & $5.423(4.595-6.400)$ & $<0.001^{*}$ & & & \\
\hline
\end{tabular}

Adjusted for age at diagnosis, year at diagnosis, sex, race, T stage, $\mathrm{N}$ stage, $\mathrm{M}$ stage, multifocality, extrathyroidal extension, radiation, surgery. * $\mathrm{P}<0.05$. ACM, all-cause mortality; DTC, differentiated thyroid cancer; $n$, number; HR, hazard ratio; $\mathrm{Cl}$, confidence interval; RERI, relative excess risk; AP, attributable proportion; SI, synergy index; PTC, papillary thyroid cancer; FTC, follicular thyroid cancer. 